\title{
Uma avaliação do PRONAF sob a ótica dos produtores rurais beneficiados no Assentamento Santa Apolônia em Mirante do Paranapanema-SP
}

\author{
André Junior Silva Wiezzel ${ }^{1}$ \\ Sandra Cristina de Oliveira ${ }^{2}$ \\ Ana Elisa Bressan Smith Lourenzani ${ }^{3}$
}

\begin{abstract}
Resumo: Atualmente, os produtores rurais assentados têm acesso, em certa medida, a um conjunto de instrumentos da política pública, dentre eles o Programa Nacional de Fortalecimento da Agricultura Familiar (PRONAF). Este, foi criado em 1996 com o objetivo de fomentar o desenvolvimento sustentável e melhorar o nível de produção, de renda e de empregos dos agricultores familiares. Avaliar o efeito do programa é importante para direcionamentos futuros. Nesse cenário, o presente trabalho tem por objetivo geral avaliar o PRONAF sob a ótica dos produtores rurais beneficiados pelo programa no assentamento Santa Apolônia em Mirante do Paranapanema-SP. Para tanto, foi realizado um levantamento (survey) e utilizado um formulário como instrumento de coleta, contendo perguntas estruturadas, visando identificar e mensurar a referida avaliação. Por intermédio da estatística descritiva, foram sintetizadas as informações socioeconômicas e financeiras dos produtores rurais, bem como as avaliações sobre os processos de implantação, produto da implantação e resultado do PRONAF. E, por meio de um modelo de regressão logística, descreveu-se especificamente a chance de um produtor rural estar satisfeito com o resultado do PRONAF como uma função da avaliação geral dos processos de implantação e do produto da implantação do programa. Os resultados apontam que há satisfação com o PRONAF, contudo, os baixos preços dos produtos agropecuários, a restrição ao crédito e a falta de maior aproximação à assistência técnica têm desestimulado os produtores. Além disso, a chance de um produtor desse assentamento estar satisfeito com o resultado do programa aumenta aproximadamente duas vezes, quanto maior for a sua satisfação com o produto da implantação, não sendo significativa a etapa de implantação.
\end{abstract}

Palavras-Chave: Assentamentos rurais. PRONAF. Avaliação. Agricultura Familiar.

An eVAluation of Pronaf From the PERSPeCtive of RURAL Producers benefited in the SANta Apolônia rural Settlement in mirante do Paranapanema-SP

Abstract: Settled farmers have access to some extent to a set of public policy instruments, including the National Program for Strengthening Family Farming (PRONAF, as its acronym in Portuguese). The program was created in 1996 to foster sustainable development and to improve the level of production, income, and employment of family farmers. Evaluating the results of the program is important for future decisions. Thus, the present work aims to evaluate PRONAF from the perspective of rural producers benefited by PRONAF at Santa Apolônia rural settlement in Mirante do Paranapanema-SP. To this end, a survey was conducted and a form was used as a collection instrument, containing structured questions. Through descriptive statistics,

\footnotetext{
${ }^{1}$ Mestre em Agronegócio e Desenvolvimento (UNESP) E-mail: andrejunior@unoeste.br

${ }^{2}$ Docente Permanente do Programa de Pós-graduação em Agronegócio e Desenvolvimento / Faculdade de Ciências e Engenharia / UNESP..E-mail: sandra.oliveira@unesp.br.

${ }^{3}$ Docente Permanente / Programa de Pós-graduação em Agronegócio e Desenvolvimento / Faculdade de Ciências e Engenharia / UNESP E-mail: ana.lourenzani@unesp.br
} 
the socioeconomic and financial information of the farmers was synthesized, as well as the evaluations on the implementation processes, the product of the implementation and the result of PRONAF. Through a logistic regression model, the chance of a farmer being satisfied with the PRONAF outcome as a function of the overall evaluation of the implementation processes and the product of the program implementation was specifically described. The results indicate that there is satisfaction with PRONAF, however, the low prices of agricultural products, the restriction of credit and the lack of closer relation with technical assistance have discouraged settled producers. In addition, the chance of a settlement producer being satisfied with the outcome of the program increases approximately twice as much as the satisfaction with the product of the implantation increases, and the implementation stage is not significantsomething old and new for the settlers, who recognize its potential for transformation of their reality and point ways for its strengthening.

KEYwORDS: Rural Settlements. PRONAF. Evaluation. Family Farming.

\section{INTRODUÇ̃̃̃O}

O agronegócio brasileiro é assunto recorrente nos telejornais e noticiários econômicos, em que, mormente, destacam as perspectivas de negócios no cenário internacional e a robustez dos indicadores econômicos desse setor, que têm contribuído de forma expressiva para a formação do Produto Interno Bruto (PIB) e para a economia brasileira. Tais resultados estão relacionados à política baseada na difusão produtivista (entre 1964 e 1984), que financiou as atividades dos produtores agropecuários mais capitalizados e localizados em certas regiões geográficas do país, que experimentaram grande avanço tecnológico e elevação dos níveis de produção. Na ocasião, os investimentos em pesquisa e extensão rural foram intensificados. Em 1970 e em 1973, respectivamente, foram instituídos o Sistema Brasileiro de Assistência Técnica e Extensão Rural (SIBRATER) e a Empresa Brasileira de Pesquisa Agropecuária (EMBRAPA). Em 1975, foi criada a Empresa Brasileira de Assistência Técnica e Extensão Rural (EMBRATER), tendo a Empresa de Assistência Técnica e Extensão Rural (EMATER) como competência em nível estadual (NEUMANN; DALBIANCO; ZARNOTT, 2005).

À margem desse cenário da agricultura moderna, encontravam-se os produtores rurais mais desprovidos, que, entre 1948 e 1964, foram beneficiários de políticas públicas assistencialistas, ancoradas ao Crédito Rural Supervisionado (CRS), liberado a algumas famílias mediante as suas necessidades e acompanhadas de acordo com o planejamento dos técnicos em extensão rural (RODRIGUES, 1997). 
Fruto das pressões sociais e do descontentamento dos produtores rurais pouco favorecidos economicamente, as políticas fundiárias começaram a se voltar para os movimentos sociais no campo ao final da década de 1950, ocasião em que ficou conhecida a palavra assentamento (BERGAMASCO; NORDER, 1996).

Ao final da década de 1980, as repetidas ações de grupos organizados, tal como o Movimento dos Trabalhadores Rurais Sem Terra (MST), seguidas da reintegração de posse dos fazendeiros e de novas ocupações, culminaram no assentamento de diversas famílias em todo o Brasil.

O termo "assentamento rural",

de uma forma genérica, pode ser definido como a criação de novas unidades de produção agrícola, por meio de políticas governamentais, visando o reordenamento do uso da terra, em benefício de trabalhadores rurais sem terra ou com pouca terra. Como o seu significado remete à fixação do trabalhador na agricultura, envolve também a disponibilidade de condições adequadas para o uso da terra e o incentivo à organização social e à vida comunitária (BERGAMASCO; NORDER, 1996).

Para o Instituto de Colonização e Reforma Agrária (INCRA), assentamento rural é "um conjunto de unidades agrícolas independentes entre si, instaladas pelo INCRA, onde originalmente existia um imóvel rural que pertencia a um único proprietário" (INCRA, 2018).

De acordo com o INCRA (2016), foram assentadas no país desde $1994 \mathrm{em}$ torno de 1.346.798.000 famílias (até abril/2016), distribuídas em 9.354 assentamentos (até fevereiro/2017). No estado de São Paulo, até o ano de 2015, foram assentadas 17.336 famílias, distribuídas em 272 assentamentos, em uma área de 345.760,41 hectares (ha). O município de Mirante do Paranapanema, localizado no extremo oeste do estado de São Paulo, possui 1559 famílias assentadas, distribuídas em 32.480,9 ha.

Para viabilizar a reprodução social desse grupo de trabalhadores rurais, tornou-se necessário disponibilizar crédito, visando à realização de investimentos e ao custeio das atividades agropecuárias. Para atingir o intento, o Decreto $\mathrm{n}^{\circ}$ 1.946/96 gerou o Programa Nacional de Fortalecimento da Agricultura Familiar (PRONAF).

Ao atender diferentes grupos de agricultores familiares, bem como demandas de diferentes grupos sociais, o PRONAF foi visto como um instrumento para valorização da diversidade da agricultura familiar e combate às desigualdades sociais e regionais (AQUINO; SCHNEIDER, 2011).

Desde sua criação, diversos estudos têm sido realizados a fim de identificar em 
que medida os objetivos principais do programa têm sido alcançados (GUANZIROLI, 2007; ROCHA; TROCCOLI; ALBUQUERQUE, 2011; SILVA; BERNARDES, 2014; LOPES et al., 2016).

Nessa direção, a questão norteadora do presente trabalho é: Qual é a avaliação do PRONAF sob a ótica dos beneficiários do programa?

Assim, o objetivo geral é avaliar o PRONAF sob a ótica dos produtores rurais beneficiados pelo programa no Assentamento Santa Apolônia, em Mirante do Paranapanema-SP. Especificamente, são descritas as características do perfil socioeconômico desses produtores, bem como a chance de um produtor rural estar satisfeito com o resultado do PRONAF como uma função da avaliação geral dos processos de implantação e do produto da implantação do programa.

Consoante os dados do Instituto Brasileiro de Geografia e Estatística (IBGE), o município de Mirante do Paranapanema possuía 17.059 habitantes à época do Censo Demográfico de 2010 (IBGE, 2017). A população é predominantemente urbana $(58,9 \%)$, mas com significativa parcela $(41,10 \%)$ vivendo no meio rural. No que diz respeito ao tamanho das unidades de produção agropecuária (UPA), prevalecem no município as áreas entre 20 e 50 ha, que correspondem a 43,5\% dos estabelecimentos, seguidos de $29,84 \%$ de UPA com área entre 10 e 20 ha (SÃO PAULO - CATI/IEA, 2008).

O assentamento Santa Apolônia é o segundo maior assentamento do município, com área de 2.657,74 ha, distribuídos em 104 lotes, tendo iniciado as suas atividades em dezembro de 1996. De acordo com os dados sociais da Fundação Instituto de Terras do Estado de São Paulo (ITESP, 2017), vivem no assentamento 326 pessoas, com predominância da faixa etária entre 20 e 59 anos (53\%). As crianças e os adolescentes (até 19 anos) representam 31\% dessa população, e os idosos, $16 \%$. Quanto ao gênero, 55\% dos assentados são homens e 45\% são mulheres. Quanto à raça, $77 \%$ de pessoas são brancas e $23 \%$ são pardas ou negras. A respeito da instrução, $94 \%$ são alfabetizados, contra $6 \%$ de analfabetos. Sobre os programas de transferência de renda ou benefícios da assistência social, contam-se 30 pessoas no assentamento na condição de beneficiários, que recebem Bolsa Família (60\%), auxílio Renda Cidadã $(16,67 \%)$ e os demais usufruem de assistência social continuada $(23,33 \%)$.

\section{REVISÃO BIBLIOGRÁFICA}

\section{PRONAF: NOVAS PERSPECTIVAS AOS TRABALHADORES RURAIS}

As políticas públicas tendem a surgir em decorrência de um alongado processo, e são normalmente precedidas por medidas governamentais paliativas e de reflexos mais imediatos no contexto do problema (SABOURIN, 2014). Mediante 
a escassez de recursos públicos para contemplar os clamores da sociedade, Vilela (2017) argumenta que o Estado termina por atender aos grupos dotados de maior hegemonia política, players de um ambiente marcado por disputas entre os agentes e representantes das distintas categorias. Nesse sentido, anteriormente ao PRONAF, houve um conjunto de medidas que culminaram com a consolidação do mesmo. No caso brasileiro, a capacidade de organização da sociedade civil tem precedido às políticas públicas voltadas aos atores sociais pouco favorecidos economicamente (SABOURIN, 2014).

Para uma melhor percepção sobre a complexa questão fundiária e agrária brasileira, faz-se mister recorrer aos fatos históricos que retratam as estratégias políticas que determinaram o atual contexto, heranças de decisões políticas que remontam à época da colonização.

Durante o período em que se acentuou a industrialização, o Brasil (e outros países do mundo) experimentou um amplo processo de urbanização. Brito (2006) avalia que a migração rural-urbana explica a maior parte da urbanização ocorrida entre 1960 e 1980, e considera que as maiores cidades eram atrativas por possuírem atividades econômicas relevantes.

No entanto, migrar para a cidade não foi a solução para todos os trabalhadores rurais. Alguns não encontraram o conforto e a estabilidade que idealizaram na vida urbana. Haviam também os que pretendiam atuar como produtores rurais - especialmente a parcela da população rural "que estava sendo praticamente expulsa em larga escala para os centros urbanos" (BERGAMASCO; NORDER, 1996), que tiveram as suas terras incorporadas por grandes fazendas ou pela agroindústria. $\mathrm{O}$ cenário era de descontentamento, já que considerável parte dos produtores rurais descapitalizados não acessavam as linhas de crédito e outros sequer possuíam terras e, por conseguinte, trabalho, pois à medida que o capital se expande, tende a dispensar trabalho devido à evolução técnica (MARTINS, 1991).

Para mudar a realidade, foi preciso engajar lutas, pois a instabilidade financeira e familiar assolava a pobreza dos trabalhadores rurais desprovidos de terras, em virtude da necessidade de vender a mão de obra, fosse como servente de pedreiro, cortador de cana, catador de papel, camelô e outros (NASCIMENTO; LOCATEL; SANTANA, 2010). Fernandes (2004) entende que os assentamentos se tornaram realidade impulsionados pela luta promovida pelos trabalhadores rurais.

\section{Agricultura Familiar e o PRONAF}

A Lei 11.326/06 trata a respeito da política nacional da agricultura familiar e sobre os empreendimentos familiares rurais (BRASIL, 2006). A lei visa promover a sustentabilidade, o respeito à diversidade e a participação do agricultor familiar 
na política nacional dessa categoria econômica. Algumas condições trazidas pela lei causam polêmica, tal como a delimitação da área para a agricultura familiar (até 4 módulos fiscais). A restrição implica em tratar sob o mesmo critério diversas particularidades da agricultura familiar, desconsiderando o contexto local/ regional/cultural, implicando sobremaneira nas possibilidades de produção e de comercialização, pois termina por englobar, na mesma condição, produtores de baixa renda com outros bastante integrados ao mercado (PEDROSO, 2014).

Ao se tratar da agricultura familiar, faz-se necessário abordar acerca da sua relevância econômica e social, pois contribui na geração de alimentos, na redução da pobreza e está "vinculada ao abastecimento do mercado interno e ao controle da inflação dos alimentos consumidos pelos brasileiros" (MDA, 2017).

Como citado anteriormente, visando o apoio à agricultura familiar, o PRONAF (Decreto $\mathrm{n}^{\circ}$. 1946/96) foi criado em $1996 \mathrm{em}$ amplitude nacional, com a finalidade de fomentar o desenvolvimento sustentável e melhorar o nível de produção, de renda e de empregos dos agricultores familiares (BRASIL, 1996).

É preciso sinalizar que, anteriormente ao PRONAF, já existiam políticas públicas voltadas para o pequeno produtor, embora, na prática, mais acessíveis ao médio e grande produtor agropecuário do Sul e Sudeste brasileiro, favorecendo a produção voltada para a exportação ou para a agroindústria (GRISA; SCHNEIDER, 2015). E, especificamente aos assentados da reforma agrária, foi instituído em 1985 o Programa de Crédito Especial para Reforma Agrária (PROCERA), que visava auxiliá-los a obter maior produção e produtividade, ampliando as perspectivas de acesso aos mercados. Apesar de o programa ter alcançado considerável parcela do seu público-alvo, foi descontinuado e incorporado ao PRONAF (GUANZIROLLI et al., 2001). Rezende (2001) explica que a carência concedida ao mutuário do PROCERA para o pagamento da dívida e as elevadas taxas de inflação da época reduziram drasticamente os fluxos de entrada do empréstimo, afirmando que este praticamente se pagava com o mero passar do tempo, fato que induziu alguns devedores a acreditar que o empréstimo não precisaria ser pago.

Em conduta inovadora, o PRONAF assegura que a política adotada vai descentralizar as decisões, já que invoca a participação do governo das três esferas (municipal, estadual e federal), da iniciativa privada, dos produtores familiares e de seus representantes, mostrando o rompimento com as antigas políticas públicas, que colocavam a questão agrária no campo de atuação do estado.

Dessa forma, o PRONAF é considerado como a primeira política pública direcionada ao produtor familiar ancorada em modelos de gestão social, e supera o mero plano de aumento da produtividade a partir do consumo de pacotes tecnológicos. Não obstante, apresenta falhas, pois ao ser concebido, visava propiciar aos agricultores familiares o aumento da produção, do emprego e da renda. Decor- 
ridas mais de duas décadas de sua implementação, não há um consenso quanto ao êxito alcançado pelo programa, sendo ressaltados a dificuldade no acesso e nos resultados do programa.

\section{Procedimentos metodológicos}

A pesquisa, realizada no município de Mirante do Paranapanema-SP, tem natureza aplicada, cuja unidade de análise são os produtores familiares que acessaram o PRONAF no assentamento Santa Apolônia. No tocante aos objetivos, é uma pesquisa descritiva com abordagem quantitativa, em virtude do uso da quantificação (técnicas estatísticas) tanto na coleta de dados quanto no tratamento e análise destes (MARTINS, 2010).

\section{Coleta de dados}

Foi utilizado o método survey para obter informações dos produtores rurais do referido assentamento, por intermédio de formulário estruturado, com questões fechadas de múltipla escolha, aplicado por entrevista direta. Foi considerada uma amostragem não probabilística por conveniência, sendo desconhecida a probabilidade de seleção de um elemento da população (HAIR et al., 2009), uma vez que o enfoque foi nos produtores rurais assentados que acessaram o PRONAF a partir do ingresso no lote. A amostra é composta por 55 participantes definidos conforme as recomendações de Ringle, Silva e Bido (2014). Para calcular o tamanho mínimo da amostra, foi utilizado o software $\mathrm{G}^{\star}$ Power 3.1.7 (FAUL et al., 2009).

O instrumento de coleta (formulário) apresentou questões sobre o perfil socioeconômico do produtor rural, além de 82 assertivas (sentenças) relacionadas ao PRONAF, das quais 79 foram validadas por Rocha, Troccoli e Albuquerque (2011), em que cada uma delas está associada a um nível de satisfação. A escala é de cinco pontos (tipo Likert), que varia de um (muito insatisfeito) até cinco (muito satisfeito), adequada para pesquisas que usam levantamentos ou entrevistas pessoais (HAIR et al., 2010).

\section{FORMA DE ANÁLISE DOS DADOS}

Os dados foram analisados descritivamente (tabelas e medidas descritivas), permitindo conhecer características socioeconômicas e a opinião dos assentados a respeito das etapas de implantação, produto da implantação e resultado do PRONAF.

A etapa de implantação visa avaliar os esforços necessários para acessar o PRONAF, incluindo a documentação, o trabalho orientador do técnico em extensão, o projeto e a tramitação dos documentos junto às instituições financeiras. A etapa de produto da implantação refere-se aos recursos obtidos por meio do PRONAF, 
de acordo com os objetivos estabelecidos no projeto, e a etapa de resultado avalia se os recursos obtidos foram eficazes quanto à melhoria da renda, da produção e das condições de vida no assentamento rural.

No final de cada etapa, os produtores avaliaram ainda, de uma forma geral (com notas de 1 a 5), as fases de implantação, produto da implantação e resultado do PRONAF. Assim, com o intuito de identificar se a avaliação geral do resultado do PRONAF pode ser descrita como uma função da avaliação geral da implantação do programa e do produto da implantação, ajustou-se um modelo de regressão logística múltiplo aos dados.

Um modelo de regressão tem por objetivo verificar a existência de uma relação funcional entre uma variável dependente (ou resposta) e uma ou mais variáveis independentes (ou preditoras).

No modelo de regressão logística múltiplo considera-se um conjunto de variáveis independentes $k$, que podem ou não ser numéricas, para prever a probabilidade da variável resposta $Y$. O modelo é dado por:

$$
Y=\beta_{0}+\beta_{1} X_{1}+\beta_{2} X_{2}+\ldots+\beta_{k} X_{k}+\varepsilon
$$

onde $\varepsilon$ são erros aleatórios desconhecidos. Pela definição de valor esperado, a média condicional para dados dicotômicos é dada por:

$$
E(Y \mid \mathbf{X}=\mathbf{x})=\beta_{0}+\beta_{1} X_{1}+\beta_{2} X_{2}+\ldots+\beta_{k} X_{k}=\pi(\mathbf{x})
$$

Como, $0 \leq E(Y \mid \mathbf{X}=\mathbf{x}) \leq 1 \quad$ então, $0 \leq \beta_{0}+\beta_{1} X_{1}+\beta_{2} X_{2}+\ldots+\beta_{k} X_{k} \leq 1$

Para assegurar que a resposta $\mathrm{Y}$ seja uma probabilidade, utiliza-se uma função de ligação entre $\pi(\mathbf{x})$ e o preditor linear $\beta_{0}+\beta_{1} X_{1}+\beta_{2} X_{2}+\ldots+\beta_{k} X_{k}$. Neste caso, considerou-se a função de ligação logit, que satisfaz:

$$
\ln \left\{\frac{\pi(\mathbf{x})}{1-\pi(\mathbf{x})}\right\}=\beta_{0}+\beta_{1} X_{1}+\beta_{2} X_{2}+\ldots+\beta_{k} X_{k} .
$$

Expressando (2) em termos de preditor linear, o modelo se resume a $Y=E(Y \mid \mathbf{X}=\mathbf{x})+\varepsilon$ em que,

$$
E(Y \mid \mathbf{X}=\mathbf{x})=\pi(\mathbf{x})=\frac{e^{\beta_{0}+\beta_{1} X_{1}+\beta_{2} X_{2}+\ldots+\beta_{k} X_{k}}}{1+e^{\beta_{0}+\beta_{1} X_{1}+\beta_{2} X_{2}+\ldots+\beta_{k} X_{k}}}
$$

O termo $\mathrm{h}\left\{\frac{\pi(\mathbf{x})}{1-\pi(\mathbf{x})}\right\}$ em (2) é chamado de resposta média logit. Se $x=x_{j}$ tal que chance $_{(j)}=\frac{\pi\left(x_{j}\right)}{1-\pi\left(x_{j}\right)}$ e se $x=x_{j}+1$ tal que chance $_{(j+1)}=\frac{\pi\left(x_{j}+1\right)}{1-\pi\left(x_{j}+1\right)}$, 
então, a razão entre a chance de um evento ocorrer em um grupo $\left(\right.$ chance $\left._{(j+1)}\right) \mathrm{e}$ deste evento ocorrer em outro grupo $\left(\right.$ chance $\left._{(j+1)}\right)$ é chamada de razão de chances $(R C)$ e é dada por (MONTGOMERY; PECK; VINING, 2001):

$$
R C=O R_{j}=\frac{\text { chance }_{(j+1)}}{\text { chance }_{(j)}}=e^{\beta_{j}}, j=1,2, \ldots, k .
$$

Para obter as variáveis preditoras significativas em um modelo de regressão logística são realizados testes de hipóteses da existência dos parâmetros $\beta_{0}, \beta_{1}, \beta_{2}, \ldots, \beta_{k}$. Assim, se a probabilidade de significância obtida por meio dos dados amostrais ( $p$-valor) for menor ou igual ao nível de significância $\alpha$ estabelecido no teste, rejeita-se a hipótese nula $\left(\beta_{\mathrm{i}}=0\right)$, e conclui-se que a variável independente $X_{\mathrm{i}}$ associada a $\beta_{\mathrm{i}}$ afeta a variável resposta $Y$.

Para analisar a validação do ajuste do modelo aos dados, os métodos mais utilizados são os de Pearson, de Deviance e de Hosmer-Lemeshow, todos baseados na distribuição qui-quadrado. Se a probabilidade de significância ( $p$-valor) para os referidos testes for menor ou igual ao nível de significância $\alpha$ estabelecido, há evidências de que o modelo é adequado aos dados (MONTGOMERY; PECK; VINING, 2001).

A qualidade do ajuste do modelo pode ainda ser avaliada por meio de alguns índices de correlação conjunta, como os índices D de Somers, Gamma de Goodman-Kruskal e Tau-a de Kendall. Os índices variam entre 0 e 1, e quanto maiores forem eles, melhor será a capacidade preditiva do modelo (HAIR et al., 2009).

Neste trabalho, os dados foram analisados usando o software Minitab, e considerou-se um nível de significância $\alpha$ de $5 \%$ para todos os testes de hipóteses realizados.

\section{RESULTADOS E DISCUSSÕES}

\section{ANÁlise do PERFIL SOCIOECONÔMICO DO PRODUTOR RURAL}

No que diz respeito à idade, foram pesquisados produtores rurais entre $32 \mathrm{e}$ 81 anos, com idade média de aproximadamente 55 anos. Em relação ao ano de ingresso no lote, a pesquisa constatou que $60,01 \%$ das famílias foram assentadas entre 1996 e 1999. No tocante aos anos dedicados à atividade agropecuária, a maior parcela $(61,86 \%)$ acumula mais de 20 anos de atividade laborativa no campo, tendo, portanto, raízes no meio rural que antecedem a época do assentamento.

Quanto à contratação de mão-de-obra, os entrevistados revelaram, em sua maioria absoluta $(92,73 \%)$, que não contratam empregados, utilizando exclusivamente a força de trabalho da família. Sobre a disponibilidade de mãode-obra, a pesquisa aponta que 78\% das famílias dispõem de 1 a 2 membros para 
laborar na produção agropecuária, e, em 23\% das famílias, tem-se entre 3 e 4 trabalhadores.

Considerando que cada lote tem área média de 21 ha, pode-se afirmar que as 55 famílias entrevistadas ocupam em torno de 1.155 ha e que geram ocupação para 114 trabalhadores. Portanto, existe em torno de 25 ha para cada família, uma vez que no assentamento encontram-se 104 famílias.

A respeito da situação financeira em relação ao PRONAF (custeio e investimento), cerca de $24 \%$ dos entrevistados possuem restrição cadastral que os impedem de realizar novas operações, ou seja, quase um quarto dos assentados foram negativados a partir do PRONAF.

Quando indagados a respeito das estratégias para gerar renda durante a estiagem, 42,83\% dos entrevistados responderam que vendem animais. Outros encontram saída na venda de leite $(16,36 \%)$ ou na comercialização de hortaliças $(7,27 \%)$. Os demais se apoiam em algum membro da família que possua renda fixa ou realiza serviços gerais.

O município de Mirante do Paranapanema possui relevância na pecuária leiteira. A pesquisa revela que dentre os 55 produtores que utilizaram o PRONAF, $38 \%$ o fizeram por conta de atividade exclusivamente voltada para investimento na pecuária leiteira, contra $9 \%$ para fins de custeio. Contudo, a grande maioria (53\%) optou pelo PRONAF custeio e investimento.

Discorrendo sobre o PRONAF custeio, têm-se como os valores mínimo e máximo das operações $\mathrm{R} \$ 1.500,00$ e $\mathrm{R} \$ 33.000,00$, respectivamente, com mediana de $\mathrm{R} \$ 5.000,00$. Tais valores representam os montantes financiados por cada mutuário em uma ou várias operações. $\mathrm{O}$ volume total das operações alcançou o montante de $\mathrm{R} \$ 269.935,00$ (valor nominal).

Acerca do número de acessos ao PRONAF custeio, a pesquisa revela que a maioria utilizou o recurso uma vez (70,60\%), sendo que $17,64 \%$ acessou 2 ou 3 vezes, e o restante, 4 vezes ou mais. Desse modo, nem todos os produtores rurais usufruem com regularidade desse importante recurso.

Sobre a situação financeira dos mutuários do PRONAF custeio, 44,12\% revelam ter pago plenamente o custeio e $26,47 \%$ não pagaram nenhuma parcela, estando, portanto, impedidos de acessar novamente o crédito. Os demais $29,41 \%$ estão com ao menos $75 \%$ do empréstimo pago ou em gozo da carência.

No tocante ao PRONAF investimento, dentre as 55 famílias entrevistadas, 50 delas utilizaram o referido recurso. Os investimentos na aquisição unicamente de gado foram de $58,33 \%$, de sorte que somente $10,41 \%$ estavam relacionados a aquisição de cavalos, carroças, eucalipto, moradias, por exemplo. Assim, 89,59\% das operações envolveram a combinação de investimento no gado com outros recursos a ele vinculados (cerca, pastagem, instalações, equipamentos e outros). 
Sobre o número de operações voltadas ao investimento, 54\% dos usuários utilizaram o benefício uma vez, seguidos de $28 \%$ que o acessaram 2 vezes e $10 \%$ que utilizaram 3 vezes. Os demais (8\%) se valeram do crédito 4 vezes ou mais. Essa situação representa um fator limitante no aprimoramento ou na ampliação da produção para a maioria dos usuários do programa. Uma vez que investimentos tendem a modernizar a base produtiva, o fato de não haver continuidade na tomada de crédito pode ser um limitante a essa modernização. Quanto aos valores observados nas operações de investimento, têm-se como valores mínimo e máximo das operações $\mathrm{R} \$ 3.000,00$ e $\mathrm{R} \$ 220.000,00$, respectivamente, com mediana de $\mathrm{R} \$ 20.000,00$. Tais valores representam os montantes financiados por cada mutuário em uma ou várias operações. O volume total das operações alcançou R\$1.615.300,00 (valor nominal).

Abordando sobre a situação financeira envolvendo o PRONAF investimento, têm-se que $24 \%$ dos mutuários pagaram toda a dívida, e $16 \%$ nada pagaram. Os demais (60\%) pagaram até $75 \%$ da dívida ou estão em carência.

\section{Análise Sobre a AVAliação do PRONAF}

$\mathrm{Na}$ avaliação do PRONAF, foram analisadas três etapas para o processo de aquisição do crédito, a sua aplicação e o resultado: a implantação do PRONAF, o produto da implantação do PRONAF e o resultado do PRONAF. Cada etapa é formada por diversas categorias, que por sua vez, são compostas por diferentes assertivas analisadas pelos produtores rurais assentados.

\section{IMPLANTAÇÃo DO PRONAF}

A etapa de implantação do PRONAF foi avaliada por intermédio de 30 assertivas, tal como mostra a Tabela 1. Tais assertivas estiveram distribuídas em cinco categorias: gestão do projeto; adequação do projeto; gestão da assistência técnica; gestão do crédito e adequação dos recursos liberados.

As respostas vinculadas à gestão do projeto avaliaram as primeiras etapas do projeto, referentes à elaboração, documentação, recursos consubstanciados, orientações do técnico de extensão sobre as condições de pagamento do PRONAF, taxa de juros, etc. Os dados revelam que o papel do técnico é fundamental para a gestão do projeto, tanto para comunicar sobre o projeto, orientar sobre documentação, orientar sobre os termos dos contratos. Tais dados estão alinhados com Guanziroli (2007), que aponta a falta da assistência técnica como um dos entraves para a maior efetividade do programa. Os agricultores mostraram nível de satisfação mais baixo com o retorno do técnico para discutir e fechar o projeto, apesar de quase $54 \%$ dos agricultores estarem satisfeitos. 
Tabela 1- Implantação do PRONAF.

\begin{tabular}{|c|c|c|c|c|c|}
\hline Gestão do Projeto & $\begin{array}{l}\text { Totalmente } \\
\text { Insatisfeito }\end{array}$ & $\begin{array}{l}\text { Parcialmente } \\
\text { Insatisfeito }\end{array}$ & $\begin{array}{l}\text { Indife- } \\
\text { rente }\end{array}$ & $\begin{array}{l}\text { Parcial- } \\
\text { mente } \\
\text { Satisfei- } \\
\text { to }\end{array}$ & $\begin{array}{l}\text { Total- } \\
\text { mente } \\
\text { Satisfei- } \\
\text { to }\end{array}$ \\
\hline Diálogo inicial com o técnico & $7,51 \%$ & $8,09 \%$ & $13,87 \%$ & $30,06 \%$ & $40,46 \%$ \\
\hline $\begin{array}{l}\text { Orientação do técnico sobre os } \\
\text { documentos }\end{array}$ & $5,79 \%$ & $3,16 \%$ & $12,63 \%$ & $33,68 \%$ & $44,74 \%$ \\
\hline $\begin{array}{l}\text { Orientação do técnico sobre o que } \\
\text { comprar }\end{array}$ & $7,22 \%$ & $4,44 \%$ & $10,00 \%$ & $42,22 \%$ & $36,11 \%$ \\
\hline $\begin{array}{l}\text { Orientação do técnico sobre juros, } \\
\text { prazos, etc }\end{array}$ & $4,93 \%$ & $0,99 \%$ & $5,91 \%$ & $41,38 \%$ & $46,80 \%$ \\
\hline $\begin{array}{l}\text { Retorno do técnico para discutir e } \\
\text { fechar o projeto }\end{array}$ & $29,09 \%$ & $1,82 \%$ & $18,18 \%$ & $23,64 \%$ & $27,27 \%$ \\
\hline $\begin{array}{l}\text { Revisão do documento pelo técni- } \\
\text { co e assinatura }\end{array}$ & $5,88 \%$ & $3,21 \%$ & $14,44 \%$ & $36,36 \%$ & $40,11 \%$ \\
\hline $\begin{array}{l}\text { Encaminhamento dos documen- } \\
\text { tos e tramitação }\end{array}$ & $18,18 \%$ & $14,55 \%$ & $10,91 \%$ & $23,64 \%$ & $32,73 \%$ \\
\hline Adequação do Projeto & $\begin{array}{l}\text { Totalmente } \\
\text { Insatisfeito }\end{array}$ & $\begin{array}{l}\text { Parcialmente } \\
\text { Insatisfeito }\end{array}$ & $\begin{array}{l}\text { Indife- } \\
\text { rente }\end{array}$ & $\begin{array}{l}\text { Parcial- } \\
\text { mente } \\
\text { Satisfei- } \\
\text { to }\end{array}$ & $\begin{array}{l}\text { Total- } \\
\text { mente } \\
\text { Satisfei- } \\
\text { to }\end{array}$ \\
\hline $\begin{array}{l}\text { Atendimento do projeto àquilo } \\
\text { que queria fazer }\end{array}$ & $0,92 \%$ & $4,61 \%$ & $12,44 \%$ & $31,34 \%$ & $50,69 \%$ \\
\hline $\begin{array}{l}\text { Contribuição do projeto na produ- } \\
\text { ção e venda na região }\end{array}$ & $0,90 \%$ & $4,50 \%$ & $10,81 \%$ & $25,23 \%$ & $58,56 \%$ \\
\hline Adequação dos recursos previstos & $1,93 \%$ & $4,83 \%$ & $14,49 \%$ & $32,85 \%$ & $45,89 \%$ \\
\hline Execução do planejamento & $0,45 \%$ & $1,79 \%$ & $14,73 \%$ & $33,93 \%$ & $49,11 \%$ \\
\hline Lucro gerado pelo planejamento & $10,91 \%$ & $14,55 \%$ & $16,36 \%$ & $16,36 \%$ & $41,82 \%$ \\
\hline Gestão da Assistência Técnica & $\begin{array}{l}\text { Totalmente } \\
\text { Insatisfeito }\end{array}$ & $\begin{array}{l}\text { Parcialmente } \\
\text { Insatisfeito }\end{array}$ & $\begin{array}{l}\text { Indife- } \\
\text { rente }\end{array}$ & $\begin{array}{l}\text { Parcial- } \\
\text { mente } \\
\text { Satisfei- } \\
\text { to }\end{array}$ & $\begin{array}{l}\text { Total- } \\
\text { mente } \\
\text { Satisfei- } \\
\text { to }\end{array}$ \\
\hline $\begin{array}{l}\text { Assistência técnica durante a } \\
\text { implantação do projeto }\end{array}$ & $8,33 \%$ & $8,33 \%$ & $17,86 \%$ & $23,81 \%$ & $41,67 \%$ \\
\hline $\begin{array}{l}\text { Assistência técnica durante a } \\
\text { execução do projeto }\end{array}$ & $10,46 \%$ & $14,38 \%$ & $17,65 \%$ & $18,30 \%$ & $39,22 \%$ \\
\hline Curso de capacitação Rural & $14,55 \%$ & $21,82 \%$ & $23,64 \%$ & $9,09 \%$ & $30,91 \%$ \\
\hline Orientação do Técnico & $16,36 \%$ & $7,27 \%$ & $14,55 \%$ & $20,00 \%$ & $41,82 \%$ \\
\hline Gestão do Crédito & $\begin{array}{l}\text { Totalmente } \\
\text { Insatisfeito }\end{array}$ & $\begin{array}{l}\text { Parcialmente } \\
\text { Insatisfeito }\end{array}$ & $\begin{array}{l}\text { Indife- } \\
\text { rente }\end{array}$ & $\begin{array}{l}\text { Parcial- } \\
\text { mente } \\
\text { Satisfei- } \\
\text { to }\end{array}$ & $\begin{array}{l}\text { Total- } \\
\text { mente } \\
\text { Satisfei- } \\
\text { to }\end{array}$ \\
\hline
\end{tabular}


Tabela 1- Implantação do PRONAF (Cont.).

\begin{tabular}{|c|c|c|c|c|c|}
\hline $\begin{array}{l}\text { Participação em reunião do banco } \\
\text { sobre o PRONAF }\end{array}$ & $6,88 \%$ & $11,25 \%$ & $33,75 \%$ & $20,00 \%$ & $28,13 \%$ \\
\hline $\begin{array}{l}\text { Orientação em reunião sobre } \\
\text { documentação }\end{array}$ & $20,00 \%$ & $16,36 \%$ & $32,73 \%$ & $14,55 \%$ & $16,36 \%$ \\
\hline $\begin{array}{l}\text { Orientação em reunião sobre juros, } \\
\text { prazos, etc }\end{array}$ & $18,18 \%$ & $14,55 \%$ & $34,55 \%$ & $14,55 \%$ & $18,18 \%$ \\
\hline $\begin{array}{l}\text { Contato posterior com o banco } \mathrm{p} / \\
\text { assinar o contrato }\end{array}$ & $18,18 \%$ & $10,91 \%$ & $30,91 \%$ & $20,00 \%$ & $20,00 \%$ \\
\hline $\begin{array}{l}\text { Conferência pelo banco do } \\
\text { material comprado }\end{array}$ & $20,00 \%$ & $9,09 \%$ & $36,36 \%$ & $21,82 \%$ & $12,73 \%$ \\
\hline $\begin{array}{l}\text { Adequação dos Recursos Libe- } \\
\text { rados }\end{array}$ & $\begin{array}{l}\text { Totalmente } \\
\text { Insatisfeito }\end{array}$ & $\begin{array}{l}\text { Parcialmente } \\
\text { Insatisfeito }\end{array}$ & $\begin{array}{l}\text { Indife- } \\
\text { rente }\end{array}$ & $\begin{array}{l}\text { Parcial- } \\
\text { mente } \\
\text { Satisfei- } \\
\text { to }\end{array}$ & $\begin{array}{l}\text { Total- } \\
\text { mente } \\
\text { Satisfei- } \\
\text { to }\end{array}$ \\
\hline Financiamento de Animais & $4,44 \%$ & $6,67 \%$ & $22,22 \%$ & $24,44 \%$ & $42,22 \%$ \\
\hline $\begin{array}{l}\text { Financiamento de máquinas e } \\
\text { equipamentos }\end{array}$ & $0,00 \%$ & $0,00 \%$ & $0,00 \%$ & $22,22 \%$ & $77,78 \%$ \\
\hline Financiamento de Cerca & $4,76 \%$ & $4,76 \%$ & $28,57 \%$ & $23,81 \%$ & $38,10 \%$ \\
\hline $\begin{array}{l}\text { Financiamento de estrutura para } \\
\text { abastecimento de água }\end{array}$ & $0,00 \%$ & $0,00 \%$ & $0,00 \%$ & $33,33 \%$ & $66,67 \%$ \\
\hline Financiamento de pastagem & $0,00 \%$ & $9,52 \%$ & $14,29 \%$ & $23,81 \%$ & $52,38 \%$ \\
\hline $\begin{array}{l}\text { Financiamento de estrutura para } \\
\text { animais }\end{array}$ & $0,00 \%$ & $9,52 \%$ & $14,29 \%$ & $23,81 \%$ & $52,38 \%$ \\
\hline Financiamento da agricultura & $30,43 \%$ & $4,35 \%$ & $21,74 \%$ & $17,39 \%$ & $26,09 \%$ \\
\hline Financiamento de outro item & $0,00 \%$ & $0,00 \%$ & $100 \%$ & $0,00 \%$ & $0,00 \%$ \\
\hline
\end{tabular}

Fonte: Elaborada pelos autores (pesquisa de campo).

$\mathrm{Na}$ etapa de adequação do projeto, foi avaliado se as necessidades da propriedade foram atendidas e se o projeto gerou lucro. O nível de satisfação foi elevado, pois os agricultores consideraram que o projeto contribuiu para o objetivo a que se propunha e para a venda de produtos. Cerca de $58 \%$ dos entrevistados consideraram que os lucros corresponderam ao esperado.

A abordagem quanto à gestão da assistência técnica tratou sobre o trabalho de assistência técnica na fase de implantação e execução do projeto. Nesse quesito, a maioria dos usuários ficou satisfeita, embora em níveis moderados. Apesar da importância da assistência técnica, menos da metade dos agricultores passaram por cursos de capacitação, cerca de $40 \%$.

No item vinculado à gestão do crédito, as questões tinham o fito de avaliar se 
a instituição financeira realizou reuniões e se essas foram esclarecedoras. Os respondentes informaram que ocorreram algumas, mas poucos participaram. As respostas não trazem níveis elevados quanto à satisfação ou à insatisfação, já que, segundo os assentados, tais assuntos eram tratados mais facilmente com o técnico da assistência técnica.

$\mathrm{O}$ item adequação dos recursos revelou que os recursos liberados foram adequados principalmente para as operações de investimento. Para as operações de custeio, o nível de satisfação foi o mais baixo entre os itens avaliados, cerca de $43 \%$. De acordo com os agricultores, isso se deve ao alto custo dos insumos, sendo que o crédito é insuficiente.

\section{Produto da Implantação}

A etapa de produto da implantação foi avaliada por intermédio de 27 assertivas, avaliadas por quatro categorias: adequação dos produtos aplicados; influência do clima na gestão dos recursos; consumo e venda de produtos; e adequação do crédito.

As questões relacionadas à adequação dos produtos aplicados voltaram-se para a avaliação da funcionalidade dos recursos adquiridos por intermédio do PRONAF, tais como, animais, cerca, poço, investimentos na lavoura, no gado e na infraestrutura produtiva.

A satisfação quanto aos recursos obtidos foi elevada entre os beneficiários do programa, especialmente quanto às aquisições de equipamentos, vacas leiteiras e estrutura para abastecimento de água, chegando até 100\% de agricultores totalmente satisfeitos. Para as atividades que demandam financiamento de custeio, os níveis de satisfação foram os mais baixos, cerca de $40 \%$.

Sobre as sentenças que tratam da influência do clima, a satisfação foi baixa ou moderada. O longo período de estiagem e o solo arenoso foram apontados pelos assentados como pontos negativos para a produção agropecuária.

As questões ligadas ao consumo e venda de produtos avaliam quanto à possibilidade de consumo ou de venda dos produtos que contaram com recursos do PRONAF, tais como, leite, queijo, hortaliças, leguminosas, bezerros e outros. Nesse norte, a satisfação foi elevada $(80,53 \%)$ quanto à venda de animais visando renovar o rebanho (vacas, touros). Contudo, para a venda de produtos agrícolas e leite, houve uma minoria satisfeita (11,54\% e $23,53 \%$, respectivamente). O que impera, nesse caso, é a insatisfação para esses produtos, na ordem de 63,46\% (produtos agrícolas) e 45,40\% (leite). Esses dados corroboram a afirmação de que a comercialização é um dos desafios enfrentados pela agricultura familiar (BUAINAIN; GARCIA, 2014).

A adequação do crédito visa avaliar se os valores médios liberados para fins de 
custeio ou de investimento foram suficientes para alavancar as atividades e melhorar a produção e a renda. Como em alguns casos existiram várias operações junto ao PRONAF, por beneficiário, optou-se por considerar o valor médio das transações. A satisfação apresentada foi moderada na maioria dos itens, exceto quanto ao prazo, já que $70 \%$ dos usuários se disseram satisfeitos quanto a isso. Houve insatisfação quanto à morosidade na liberação dos recursos $(32,00 \%)$ e sobre o resultado da renegociação das dívidas $(32,73 \%)$.

Tabela 2 - Produto da Implantação do PRONAF.

\begin{tabular}{|c|c|c|c|c|c|}
\hline $\begin{array}{c}\text { Adequação dos Produtos } \\
\text { Aplicados }\end{array}$ & $\begin{array}{l}\text { Totalmente } \\
\text { Insatisfeito }\end{array}$ & $\begin{array}{l}\text { Parcialmente } \\
\text { Insatisfeito }\end{array}$ & Indiferente & $\begin{array}{l}\text { Parcialmente } \\
\text { Satisfeito }\end{array}$ & $\begin{array}{l}\text { Totalmen- } \\
\text { te Satis- } \\
\text { feito }\end{array}$ \\
\hline $\begin{array}{l}\text { Aquisição e atendimento de } \\
\text { máquinas e equipamentos }\end{array}$ & $0,00 \%$ & $0,00 \%$ & $0,00 \%$ & $11,11 \%$ & $88,89 \%$ \\
\hline $\begin{array}{l}\text { Construção e atendimento de } \\
\text { estrutura para os animais }\end{array}$ & $0,00 \%$ & $20,00 \%$ & $20,00 \%$ & $40,00 \%$ & $20,00 \%$ \\
\hline $\begin{array}{l}\text { Aquisição e atendimento de } \\
\text { cerca }\end{array}$ & $5,26 \%$ & $5,26 \%$ & $26,32 \%$ & $21,05 \%$ & $42,11 \%$ \\
\hline $\begin{array}{l}\text { Construção e atendimento de } \\
\text { abastecimento de água }\end{array}$ & $0,00 \%$ & $0,00 \%$ & $0,00 \%$ & $0,00 \%$ & $100 \%$ \\
\hline $\begin{array}{l}\text { Aquisição de animal fêmea } \\
\text { (vaca,porca, galinha, etc) }\end{array}$ & $1,95 \%$ & $0,00 \%$ & $8,78 \%$ & $33,17 \%$ & $56,10 \%$ \\
\hline $\begin{array}{l}\text { Formação e atendimento de } \\
\text { pasto-capineira }\end{array}$ & $0,00 \%$ & $0,00 \%$ & $61,54 \%$ & $23,08 \%$ & $15,38 \%$ \\
\hline $\begin{array}{c}\text { Plantação de } \\
\text { lavoura-roçado }\end{array}$ & $25,00 \%$ & $12,50 \%$ & $20,83 \%$ & $33,33 \%$ & $8,33 \%$ \\
\hline $\begin{array}{l}\text { Aquisição ou construção de } \\
\text { outros itens }\end{array}$ & $0,00 \%$ & $0,00 \%$ & $16,67 \%$ & $83,33 \%$ & $0,00 \%$ \\
\hline $\begin{array}{l}\text { Influência do Clima na } \\
\text { Gestão dos Recursos }\end{array}$ & $\begin{array}{l}\text { Totalmente } \\
\text { Insatisfeito }\end{array}$ & $\begin{array}{l}\text { Parcialmente } \\
\text { Insatisfeito }\end{array}$ & Indiferente & $\begin{array}{l}\text { Parcialmente } \\
\text { Satisfeito }\end{array}$ & $\begin{array}{l}\text { Totalmen- } \\
\text { te Satis- } \\
\text { feito }\end{array}$ \\
\hline $\begin{array}{l}\text { Plantação de } \\
\text { lavoura anual }\end{array}$ & $15,00 \%$ & $15,00 \%$ & $35,00 \%$ & $35,00 \%$ & $0,00 \%$ \\
\hline $\begin{array}{l}\text { Formação de } \\
\text { pasto-capineira }\end{array}$ & $0,00 \%$ & $7,79 \%$ & $54,55 \%$ & $31,17 \%$ & $6,49 \%$ \\
\hline $\begin{array}{l}\text { Criação de } \\
\text { animais }\end{array}$ & $3,42 \%$ & $10,96 \%$ & $36,99 \%$ & $38,36 \%$ & $10,27 \%$ \\
\hline $\begin{array}{l}\text { Estrutura financiada (poço, } \\
\text { aviário, cocheira, cerca, etc) }\end{array}$ & $0,00 \%$ & $0,00 \%$ & $0,00 \%$ & $44,44 \%$ & $55,56 \%$ \\
\hline $\begin{array}{l}\text { Consumo e Venda de } \\
\text { Produto }\end{array}$ & $\begin{array}{l}\text { Totalmente } \\
\text { Insatisfeito }\end{array}$ & $\begin{array}{l}\text { Parcialmente } \\
\text { Insatisfeito }\end{array}$ & Indiferente & $\begin{array}{l}\text { Parcialmente } \\
\text { Satisfeito }\end{array}$ & $\begin{array}{l}\text { Totalmen- } \\
\text { te Satis- } \\
\text { feito }\end{array}$ \\
\hline $\begin{array}{l}\text { Venda ou troca de animais } \\
\text { financiados }\end{array}$ & $2,11 \%$ & $3,16 \%$ & $14,21 \%$ & $46,32 \%$ & $34,21 \%$ \\
\hline
\end{tabular}


Tabela 2 - Produto da Implantação do PRONAF (Cont.).

\begin{tabular}{|c|c|c|c|c|c|}
\hline $\begin{array}{l}\text { Venda ou troca de cria(s) de } \\
\text { animais financiados }\end{array}$ & $1,96 \%$ & $9,80 \%$ & $25,49 \%$ & $35,29 \%$ & $27,45 \%$ \\
\hline $\begin{array}{l}\text { Consumo de leite de animal } \\
\text { financiado }\end{array}$ & $9,80 \%$ & $5,88 \%$ & $9,80 \%$ & $9,80 \%$ & $64,71 \%$ \\
\hline $\begin{array}{l}\text { Venda de leite de animal } \\
\text { financiado }\end{array}$ & $31,37 \%$ & $13,73 \%$ & $31,37 \%$ & $9,80 \%$ & $13,73 \%$ \\
\hline $\begin{array}{l}\text { Consumo de produtos de- } \\
\text { rivados do leite de animal } \\
\text { financiado }\end{array}$ & $13,73 \%$ & $15,69 \%$ & $35,29 \%$ & $17,65 \%$ & $17,65 \%$ \\
\hline $\begin{array}{l}\text { Venda de produtos derivados } \\
\text { do leite de animal financiado }\end{array}$ & $19,61 \%$ & $17,65 \%$ & $56,86 \%$ & $3,92 \%$ & $1,96 \%$ \\
\hline $\begin{array}{l}\text { Consumo de produtos agrí- } \\
\text { colas financiados }\end{array}$ & $28,85 \%$ & $30,77 \%$ & $23,08 \%$ & $5,77 \%$ & $11,54 \%$ \\
\hline $\begin{array}{l}\text { Venda de produtos agrícolas } \\
\text { financiados }\end{array}$ & $40,38 \%$ & $23,08 \%$ & $25,00 \%$ & $3,85 \%$ & $7,69 \%$ \\
\hline $\begin{array}{l}\text { Venda ou consumo de outros } \\
\text { produtos agropecuários } \\
\text { financiados }\end{array}$ & $0,00 \%$ & $0,00 \%$ & $0,00 \%$ & $100 \%$ & $0,00 \%$ \\
\hline Adequação do Crédito & $\begin{array}{l}\text { Totalmente } \\
\text { Insatisfeito }\end{array}$ & $\begin{array}{l}\text { Parcialmente } \\
\text { Insatisfeito }\end{array}$ & Indiferente & $\begin{array}{l}\text { Parcialmente } \\
\text { Satisfeito }\end{array}$ & $\begin{array}{l}\text { Totalmen- } \\
\text { te Satis- } \\
\text { feito }\end{array}$ \\
\hline $\begin{array}{l}\text { Satisfação com o limite de } \\
\text { crédito que pegou }\end{array}$ & $10,91 \%$ & $12,73 \%$ & $25,45 \%$ & $21,82 \%$ & $29,09 \%$ \\
\hline $\begin{array}{l}\text { Atraso no pagamento e des- } \\
\text { valorização do dinheiro }\end{array}$ & $22,00 \%$ & $10,00 \%$ & $12,00 \%$ & $32,00 \%$ & $24,00 \%$ \\
\hline $\begin{array}{c}\text { Uso e atraso do crédito para } \\
\text { custeio }\end{array}$ & $18,92 \%$ & $13,51 \%$ & $10,81 \%$ & $40,54 \%$ & $16,22 \%$ \\
\hline $\begin{array}{l}\text { Pagamento de parcela, des- } \\
\text { conto ou quitação do crédito }\end{array}$ & $29,09 \%$ & $1,82 \%$ & $5,45 \%$ & $32,73 \%$ & $30,91 \%$ \\
\hline $\begin{array}{l}\text { Prazo de pagamento/ venci- } \\
\text { mento do crédito }\end{array}$ & $3,64 \%$ & $7,27 \%$ & $18,18 \%$ & $20,00 \%$ & $50,91 \%$ \\
\hline $\begin{array}{l}\text { Renegociação do financia- } \\
\text { mento }\end{array}$ & $14,55 \%$ & $18,18 \%$ & $12,73 \%$ & $27,27 \%$ & $27,27 \%$ \\
\hline
\end{tabular}

Fonte: Elaborada pelos autores (pesquisa de campo).

\section{Resultado Do PRONAF}

A etapa de resultado do PRONAF foi avaliada por intermédio de 23 assertivas, distribuídas em quatro categorias: qualidade de vida, geração de emprego e renda, capacidade produtiva e fixação no campo (Tabela 3).

As assertivas que tratam sobre a qualidade de vida buscaram captar a influência do PRONAF sobre aspectos como a alimentação, moradia, remédios, vestuário e possibilidadedeajudafinanceiraaosfamiliares.Cercade64\%dosusuáriosapontaram que houve melhoria na alimentação da família, mas se observou insatisfação 
em vários itens, notadamente naquele com respeito ao transporte $(52,73 \%)$.

Em relação à geração de emprego e renda, as questões voltaram-se para a geração de renda e oportunidade de trabalho para a família, recaindo também sobre a capacidade financeira para remunerar um trabalhador externo ou ajudar um membro da família. Nesses quesitos, a satisfação foi moderada em relação à renda, mas elevada quanto à geração de trabalho. Contrariamente, houve elevada insatisfação pelo fato de a maioria não conseguir pagar um trabalhar externo $(78,18 \%)$ ou ajudar outro membro da família $(81,82 \%)$.

As variáveis voltadas à capacidade produtiva avaliaram a opinião dos assentados sobre o aumento da produção, da qualidade e dos meios de trabalho para a produção, após a adesão ao PRONAF. Apesar de autores como Guanziroli (2007) e Mattei (2014) afirmarem que há dificuldade em operacionalização financeira do PRONAF, a maioria das respostas convergiram para elevada satisfação quanto ao fato de o PRONAF ter sido capaz de melhorar a produção tanto em termos de quantidade como em qualidade dos produtos.

As questões sobre a fixação no campo objetivam mensurar a opinião dos assentados a respeito da importância do PRONAF para viver e progredir no campo, e sobre os resultados advindos do programa. A avaliação desse quesito apontou elevada satisfação, especialmente quanto à importância do PRONAF para o progresso no campo $(80 \%)$ e satisfação dos assentados em viver no meio rural $(90,91 \%)$.

Tabela 3- Resultado do PRONAF.

\begin{tabular}{|c|c|c|c|c|c|}
\hline $\begin{array}{l}\text { Qualidade de } \\
\text { Vida }\end{array}$ & $\begin{array}{l}\text { Totalmente } \\
\text { Insatisfeito }\end{array}$ & $\begin{array}{l}\text { Parcialmente } \\
\text { Insatisfeito }\end{array}$ & $\begin{array}{l}\text { Indife- } \\
\text { rente }\end{array}$ & $\begin{array}{c}\text { Parcial- } \\
\text { mente } \\
\text { Satisfeito }\end{array}$ & $\begin{array}{l}\text { Totalmente } \\
\text { Satisfeito }\end{array}$ \\
\hline Alimentação & $5,45 \%$ & $3,64 \%$ & $27,27 \%$ & $14,55 \%$ & $49,09 \%$ \\
\hline $\begin{array}{l}\text { Acesso a } \\
\text { Água }\end{array}$ & $9,09 \%$ & $9,09 \%$ & $47,27 \%$ & $23,64 \%$ & $10,91 \%$ \\
\hline $\begin{array}{l}\text { Moradia (construção, reforma e reparo } \\
\text { da casa) }\end{array}$ & $23,64 \%$ & $12,73 \%$ & $25,45 \%$ & $12,73 \%$ & $25,45 \%$ \\
\hline Aquisição de roupas e calçados & $21,82 \%$ & $16,36 \%$ & $23,64 \%$ & $14,55 \%$ & $23,64 \%$ \\
\hline $\begin{array}{l}\text { Aquisição de remédios ou exames } \\
\text { médicos }\end{array}$ & $21,82 \%$ & $16,36 \%$ & $21,82 \%$ & $16,36 \%$ & $23,64 \%$ \\
\hline $\begin{array}{l}\text { Acesso a meios de transporte (compra } \\
\text { de passagem, moto, carro, etc) }\end{array}$ & $36,36 \%$ & $16,36 \%$ & $10,91 \%$ & $14,55 \%$ & $21,82 \%$ \\
\hline $\begin{array}{l}\text { Contribuição aos } \\
\text { Familiares }\end{array}$ & $45,45 \%$ & $20,00 \%$ & $9,09 \%$ & $10,91 \%$ & $14,55 \%$ \\
\hline $\begin{array}{l}\text { Geração de Emprego } \\
\text { e Renda }\end{array}$ & $\begin{array}{l}\text { Totalmente } \\
\text { Insatisfeito }\end{array}$ & $\begin{array}{l}\text { Parcialmente } \\
\text { Insatisfeito }\end{array}$ & $\begin{array}{l}\text { Indife- } \\
\text { rente }\end{array}$ & $\begin{array}{l}\text { Parcial- } \\
\text { mente } \\
\text { Satisfeito }\end{array}$ & $\begin{array}{l}\text { Totalmente } \\
\text { Satisfeito }\end{array}$ \\
\hline
\end{tabular}


Tabela 3- Resultado do PRONAF (cont.)

\begin{tabular}{|c|c|c|c|c|c|}
\hline $\begin{array}{l}\text { Melhoria da renda em certas épocas } \\
\text { do ano }\end{array}$ & $9,09 \%$ & $9,09 \%$ & $27,27 \%$ & $32,73 \%$ & $21,82 \%$ \\
\hline Geração de renda pequena e esporádica & $9,09 \%$ & $10,91 \%$ & $25,45 \%$ & $29,09 \%$ & $25,45 \%$ \\
\hline Melhoria da renda por ter estoque & $9,09 \%$ & $12,73 \%$ & $23,64 \%$ & $25,45 \%$ & $29,09 \%$ \\
\hline Geração de oportunidade de trabalho & $3,64 \%$ & $5,45 \%$ & $5,45 \%$ & $32,73 \%$ & $52,73 \%$ \\
\hline Geração de mais serviço & $3,64 \%$ & $0,00 \%$ & $3,64 \%$ & $25,45 \%$ & $67,27 \%$ \\
\hline $\begin{array}{c}\text { Contribuição para a família trabalhar } \\
\text { na propriedade }\end{array}$ & $9,09 \%$ & $0,00 \%$ & $9,09 \%$ & $30,91 \%$ & $50,91 \%$ \\
\hline $\begin{array}{l}\text { Contribuição para pagar um trabalha- } \\
\text { dor de fora }\end{array}$ & $61,82 \%$ & $16,36 \%$ & $9,09 \%$ & $10,91 \%$ & $1,82 \%$ \\
\hline $\begin{array}{l}\text { Contribuição para a família trabalhar } \\
\text { fora da propriedade }\end{array}$ & $61,82 \%$ & $20,00 \%$ & $5,45 \%$ & $5,45 \%$ & $7,27 \%$ \\
\hline Capacidade Produtiva & $\begin{array}{l}\text { Totalmente } \\
\text { Insatisfeito }\end{array}$ & $\begin{array}{l}\text { Parcialmente } \\
\text { Insatisfeito }\end{array}$ & $\begin{array}{l}\text { Indife- } \\
\text { rente }\end{array}$ & $\begin{array}{l}\text { Parcial- } \\
\text { mente } \\
\text { Satisfeito }\end{array}$ & $\begin{array}{c}\text { Totalmente } \\
\text { Satisfeito }\end{array}$ \\
\hline $\begin{array}{l}\text { Contribuição para o aumento da pro- } \\
\text { dução }\end{array}$ & $7,27 \%$ & $9,09 \%$ & $12,73 \%$ & $32,73 \%$ & $38,18 \%$ \\
\hline $\begin{array}{l}\text { Contribuição para produção com mais } \\
\text { apoio }\end{array}$ & $7,27 \%$ & $7,27 \%$ & $12,73 \%$ & $27,27 \%$ & $45,45 \%$ \\
\hline $\begin{array}{c}\text { Contribuição para produção com mais } \\
\text { qualidade }\end{array}$ & $16,36 \%$ & $7,27 \%$ & $16,36 \%$ & $29,09 \%$ & $30,91 \%$ \\
\hline $\begin{array}{c}\text { Contribuição para produção com } \\
\text { outros meios de trabalho (ferramenta } \\
\text { nova, moto, etc) }\end{array}$ & $11,11 \%$ & $16,67 \%$ & $24,07 \%$ & $20,37 \%$ & $27,78 \%$ \\
\hline Fixação no Campo & $\begin{array}{l}\text { Totalmente } \\
\text { Insatisfeito }\end{array}$ & $\begin{array}{l}\text { Parcialmente } \\
\text { Insatisfeito }\end{array}$ & $\begin{array}{l}\text { Indife- } \\
\text { rente }\end{array}$ & $\begin{array}{l}\text { Parcial- } \\
\text { mente } \\
\text { Satisfeito }\end{array}$ & $\begin{array}{c}\text { Totalmente } \\
\text { Satisfeito }\end{array}$ \\
\hline $\begin{array}{c}\text { Contribuição para o progresso no } \\
\text { campo }\end{array}$ & $12,73 \%$ & $1,82 \%$ & $5,45 \%$ & $7,27 \%$ & $72,73 \%$ \\
\hline $\begin{array}{l}\text { Resultado na } \\
\text { Propriedade }\end{array}$ & $14,55 \%$ & $7,27 \%$ & $10,91 \%$ & $18,18 \%$ & $49,09 \%$ \\
\hline Contribuição para a fixação campo & $7,27 \%$ & $7,27 \%$ & $9,09 \%$ & $16,36 \%$ & $60,00 \%$ \\
\hline $\begin{array}{l}\text { Satisfação de viver } \\
\text { no campo }\end{array}$ & $3,64 \%$ & $1,82 \%$ & $3,64 \%$ & $14,55 \%$ & $76,36 \%$ \\
\hline
\end{tabular}

Fonte: Elaborada pelos autores (pesquisa de campo).

Posteriormente, os produtores avaliaram de uma forma geral (com notas de 1 a 5), as etapas de implantação e do produto da implantação do PRONAF. Para verificar se a avaliação geral do resultado do PRONAF ( $Y=0$, se não satisfeito; $Y=1$, se satisfeito) pode ser descrita como uma função da avaliação geral da implantação do programa $\left(X_{1}\right)$ e do produto da implantação $\left(X_{2}\right)$, foi ajustado um modelo de 
regressão logística múltiplo aos dados.

Assim, obteve-se um modelo no qual apenas a variável $X_{2}$ (produto da implantação) $[p$-valor $=0,0024]$ foi considerada significativa, ao nível de significância de $5 \%$. Assim, o modelo de melhor ajuste pode ser resumido e descrito como

$$
\begin{aligned}
& \hat{\pi}(\mathbf{x})=P(Y=1)=\frac{\exp (Y)}{(1+\exp (Y))} \\
& Y=-1, \mathbb{4}+0,718 X_{2}
\end{aligned}
$$

O coeficiente positivo da variável $X_{2}(0,718)$, aliado à sua razão de chances $(R C$ $=2,0505$ ), sugere que quanto maior o índice de satisfação geral do produtor rural com respeito ao produto da implantação do programa, maior a chance de este estar satisfeito com o resultado do PRONAF; e essa chance aumenta aproximadamente duas vezes (quando comparado àquele que não se diz satisfeito) para cada posição acrescida na nota atribuída a essa etapa.

Os resultados possibilitam inferir ainda que, independentemente do nível de satisfação (ou insatisfação) geral do produtor assentado quanto à etapa de implantação do programa, esta não apresenta influência na satisfação (ou insatisfação) deste produtor quanto ao resultado do PRONAF.

No que diz respeito ao ajuste do modelo, uma análise da regressão geral por meio da razão de verossimilhança (que testa a hipótese nula de que todos os coeficientes associados às variáveis explicativas são iguais a zero versus a alternativa de que pelo menos um destes não é igual a zero) mostrou $p$-valor de 0,0046 , indicando que há evidências suficientes para afirmar que ao menos um dos coeficientes é diferente de zero, dado que este está abaixo do nível de significância estabelecido (5\%).

Em seguida foram avaliadas a qualidade do ajuste dos dados. Como os índices obtidos como $p$-valores variam de 0,388 a 0,550 e estes são maiores do que o nível de significância de 5\%, o teste não rejeita a hipótese nula de um ajuste adequado do modelo logístico aos dados.

Finalmente, no que diz respeito à associação entre os valores da variável resposta e as probabilidades previstas pelo modelo logístico, os testes de correlação que verificam a capacidade preditiva do modelo estimado, apresentam valores acima de 50\%, mostrando que o modelo logístico ajustado tem boa capacidade para prever a probabilidade de o produtor assentado estar satisfeito com o resultado do PRONAF, dada a variável explicativa significativa ao modelo (produto da implantação).

\section{Conclusão}


Na sua criação, o PRONAF teve como objetivo fomentar o desenvolvimento sustentável e melhorar o nível de produção, de renda e de empregos dos agricultores familiares (BRASIL, 1996). Entretanto, o êxito do programa depende da combinação de recursos e do comportamento de distintos agentes econômicos, de modo a gerar as condições necessárias para a alavancagem da produção, manutenção do capital de giro, da renda e dos ativos geradores de caixa. Assim, avaliar o PRONAF sob a ótica dos beneficiários foi importante para compreender o efeito dessa política sobre os produtores rurais assentados.

Ainda que os relatos tenham apontado, no geral, a predominância de indicadores positivos de satisfação quanto à implantação, produto da implantação e resultados do PRONAF, comprovou-se estatisticamente que o processo de produto da implantação foi o que significativamente contribuiu para a satisfação quanto aos resultados do programa para os produtores rurais do assentamento Santa Apolônia, em Mirante do Paranapanema. Ou seja, ainda que a etapa de implantação do programa seja indispensável, a adequação (ou não) dos produtos aplicados e do crédito, bem como do clima na gestão dos recursos e das formas de consumo e venda de seus produtos, são os fatores que, na visão de tais produtores, contribuem efetivamente para resultados positivos (ou negativos) que proporcionam qualidade de vida, geração de emprego e renda, capacidade produtiva e fixação no campo.

A pesquisa de campo indicou que há relatos sobre a existência de entraves burocráticos e dificuldades quanto à tramitação dos documentos e procedimentos - uma espécie de desordem quanto aos documentos - que, segundo vários assentados (até entre os que negociaram várias vezes com o banco), desapareciam no banco, sendo que eles se obrigavam a reapresentá-los. Esses dados corroboram às conclusões de Guanziroli (2007) e Mattei (2014). Mesmo diante desses apontamentos, alguns declaram-se por satisfeitos, pois consideram o ato de reclamar como "ingratidão". Outros avaliaram positivamente, pois nada possuíam antes do PRONAF e, mesmo com as dificuldades, conseguiram alcançar melhorias.

Quanto ao relacionamento entre os assentados e os técnicos, ou ainda, com respeito aos apontamentos tecidos sobre as instituições financeiras que, na visão de muitos assentados, visam satisfazer os produtores rurais mais capitalizados, faz-se necessária a aproximação entre os assentados e a assistência técnica. Nesse sentido, Oliveira et al. (2016) apontam que anotações restritivas que impedem o acesso ao crédito rural pelos produtores assentados envolvem aspectos relacionados à falta de acompanhamento técnico em suas propriedades. Além disso, é preciso que haja a redução do distanciamento entre os assentados e a instituição bancária, pois tais lacunas não permitem a otimização dos recursos, independentemente dos arquétipos que permeiam a visão dos assentados ao avaliar o banco e os técnicos. 
O nível de insatisfação quanto à venda de produtos agropecuários é marcante. De forma quase unânime, os assentados relatam que não obtiveram o preço esperado em seus produtos agrícolas. O comportamento dos preços no mercado independe da ação dos agricultores. Isso pode ser explicado pelo fato de haver diferentes variáveis externas e incontroláveis, como a dotação de infraestrutura logística e comportamento da demanda, por exemplo. Portanto, projetos que levem em consideração um estudo sobre a dinâmica do mercado poderiam ajudar a reduzir essas incertezas. Alguns agricultores ainda sofreram perdas nas lavouras, quer seja por geada, excesso de chuva em alguns períodos ou em função da baixa umidade do solo durante a estiagem.

Os depoimentos retratam que a situação era melhor quando podiam vender para a Companhia Nacional de Abastecimento (CONAB), organizadora do Programa de Aquisição de Alimentos (PAA), criado pela Lei 10.696/03. A partir de 2013, o programa entrou em declínio e recursos orçamentários foram reduzidos em todo o país, causando impacto negativo sobre os agricultores que contavam com esse canal de comercialização (HENTZ; HESPANHOL, 2019).

Para alguns assentados, a disponibilidade dos recursos do PRONAF não garantiu a manutenção do capital de giro e a preservação dos recursos geradores de caixa. Aos que não recuperaram o investimento realizado (gado, lavoura, eucalipto) por conta de intempéries ou baixo preço de venda, remanesceram as dívidas junto ao PRONAF, levando o produtor à insatisfação. A perda desses ativos impossibilita a capacidade de equilíbrio financeiro da atividade, gerando uma quebra no ciclo operacional (tempo necessário para produzir e vender) e financeiro (fluxos de pagamentos após os recebimentos).

O desequilíbrio financeiro fica contundente quando o produtor se torna inadimplente, uma vez que não consegue angariar novos recursos e reequilibrar os ciclos. De acordo com alguns assentados, está praticamente impossível obter novamente os recursos do PRONAF, já que o banco tem exigido um fiador para concretizar a operação.

O cenário aponta que considerável parcela dos assentados experimenta dificuldades, especialmente quanto ao crédito, renegociação das dívidas e acesso às tecnologias (ativos e conhecimento técnico voltado à produção), fatores que dificultam os esforços para melhorar a produção e a renda.

$\mathrm{O}$ que parece comum aos produtores rurais assentados é a importância que atribuem ao PRONAF, e o concebem como indispensável para a reprodução do seu grupo social e o bem-estar das suas famílias. Assim, mais esforços devem ser dispendidos no sentindo de aumentar a efetividade do programa entre os assentados. 


\section{REFERÊNCIAS}

AQUINO, J. R. de.; SCHNEIDER, S. Doze anos da política de crédito do PRONAF no Brasil (1996-2008): Uma reflexão crítica. Revista de Extensão e Estudos Rurais, v. 1, n. 2, p. 309-347, 2011.

BERGAMASCO, S. M.; NORDER, L. A. C. O que são assentamentos rurais. 1. ed. São Paulo: Brasiliense, 1996.

BRASIL, Decreto 1.946/96 de 28 de junho de 1996 - Cria o PRONAF e dá outras providências. Disponível em: <http://www.planalto.gov.br/ccivil_03/decreto/ d1946.htm> Acesso em: 01 abr. 2017.

BRASIL, Lei 11.326/06 de 24 de julho de 2006 - Estabelece as diretrizes para a formulação da Política Nacional da Agricultura Familiar e Empreendimentos Familiares Rurais. Disponível em: <http://www.planalto.gov.br/ccivil_03/_ato20042006/2006/lei/l11326.htm> Acesso em: 03 dez. 2017.

BRASIL. Ministério do Desenvolvimento Agrário (MDA). Brasil: 70\% dos alimentos que vão à mesa dos brasileiros são da agricultura familiar. Brasil, 2017. Disponível em: <http://www.mda.gov.br/sitemda/noticias/brasil-70-dos-alimentos-que-vão-à-mesa-dos-brasileiros-são-da-agricultura-familiar> Acesso em: 26 nov. 2017.

BRITO, F. O deslocamento da população brasileira para as metrópoles. Estudos Avançados, v. 57, p. 221-236, 2006. Disponível em: <http://www.scielo.br/pdf/ea/ v20n57/a17v2057.pdf>. Acesso em: 27 mar. 2017.

BUAINAIN, A. M., GARCIA, J, R. Agricultura Familiar e transformações recentes do mercado. In: DOULA, S. M. et al. (Orgs.). A agricultura familiar em face das transformações na dinâmica recente dos mercados. 1ed.Viçosa, MG: Suprema, p. 89-126, 2014.

FAUL, F. et al. $G^{\star}$ Power 3: A flexible statistical power analysis program for the social, behavioral, and biomedical sciences. Behavior Research Methods, v. 39, p. 175-191, 2007. Disponível em: < http://www.gpower.hhu.de/> Acesso em: 02. mar. 2017.

FERNANDES, B. M. 20 anos do MST e a perspectiva de reforma agrária no gov- 
erno Lula. In: OLIVEIRA, A. U.; MARQUES, M. I. (Org.). O Campo no Século XXI. São Paulo: Editora Casa Amarela; Editora Paz e Terra, 2004, p. 273-294. Disponível em: <http://biblioteca.planejamento.gov.br/biblioteca-tematica-1/textos/ desenvolvimento-agrario/texto-42-20-anos-do-mst-e-a-perspectiva-da-reformaagraria-no-governo-lula.pdf> Acesso em: 15 out. 2017.

GRISA, C.; SCHNEIDER, S. (Org.). Políticas de Desenvolvimento Rural no Brasil. 1. ed. Porto Alegre: UFRGS, 2015. v. 1. Disponível em: <http://www.ufrgs. $\mathrm{br} / \mathrm{pgdr} /$ publicacoes/livros/outras-publicacoes/politicas-publicas-de-desenvolvimento-rural-no-brasil>. Acesso em: 13 abr. 2017.

GUANZIROLI, C. PRONAF dez anos depois: resultados e perspectivas para o desenvolvimento rural. Revista de Economia e Sociologia Rural, v. 45, n. 2, p. 301-328, June 2007. Disponível em: http://www.scielo.br/scielo.php?script=sci arttext\&pid=S0103-20032007000200004\&lng=en\&nrm=iso $>$. Acesso em: 26 set. 2019.

GUANZIROLI, C. et al. Agricultura Familiar e Reforma Agrária no Século XXI. Rio de Janeiro: Garamond, 2001. 288p.

IBGE (Instituto Brasileiro de Geografia e Estatística). Indicadores Sociais Municipais: uma análise dos resultados do universo do Censo Demográfico. Brasil, 2017. Disponível em <https://ww2.ibge.gov.br/home/estatistica/populacao/ censo2010/indicadores_sociais_municipais/default_indicadores_sociais_municipais.shtm>. Acesso em: 10 fev. 2017.

INCRA (Instituto Nacional de Colonização e Reforma Agrária). Assentamentos Criados. Brasil, 2016. Disponível em: <http://www.incra.gov.br/sites/default/files/uploads/reforma-agraria/questao-agraria/reforma-agraria/pas_criados_2016.pdf>. Acesso em: 16 ago. 2016.

ITESP (Instituto de Terras do Estado de São Paulo). Assentamentos. São Paulo, 2017. Disponível em: <http://www.ITESP.sp.gov.br/br/info/acoes/assentamentos. aspx> Acesso em: 24 nov. 2017.

HAIR, J. F. et al. Análise multivariada de dados. 6. Ed. São Paulo: Bookman, $01 / 2009$.

HAIR, J. F. et al. Fundamentos de Pesquisa de Marketing. Porto Alegre: Book- 
man, 2010.

HENTZ, C.; HESPANHOL, R. A. M. O Programa de Aquisição de Alimentos - PAA: a evolução de uma política pública múltipla. Geosul, v. 34, n. 72, p. 415434, jul. 2019. Disponível em: https://periodicos.ufsc.br/index.php/geosul/article/ view/1982-5153.2019v34n72p415/40314>. Acesso em: 07 out. 2019.

LOPES, P. F. et al. O PRONAF e as racionalidades da agricultura familiar. Estudos Sociedade e Agricultura, vol. 24, n. 1, p. 70-84, abr. 2016. Disponível em: <http:// r1.ufrrj.br/esa/V2/ojs/index.php/esa/article/view/669>. Acesso em: 09 nov. 2017.

MARTINS, J. S. Expropriação e violência a questão política no campo, 3. ed. São Paulo: Editora Hucitec, 1991.

MARTINS, R. A. Abordagens quantitativa e qualitativa. In: MIGUEL, P. A. M. (org.). Metodologia de pesquisa em engenharia de produção e gestão de operações. Rio de Janeiro: Elsevier, 2010.

MATTEI, L. Evolução do crédito do PRONAF para as categorias de agricultores familiares A e A/C entre 2000 e 2010. Revista Econômica do Nordeste, v. 45, n. 3, p. 58-69, jul-set., 2014. Disponível em: < https://ren.emnuvens.com.br/ren/article/view/119/98> Acesso em: 8 set. 2019.

MONTGOMERY, D. C.; PECK, E. A.; VINING, G. G. Introduction to linear regression analysis. New York: John Wiley \& Sons, 2001.

NASCIMENTO, A. C. S., LOCATEL, C. D., SANTANA, G. C. P. Estratégias de reprodução social do camponês. In: XVI Encontro Nacional de Geógrafos, 2010, Porto Alegre. Anais... XVI Encontro Nacional de Geógrafos. Porto Alegre: ENG, 2010. p. 1-8. Disponível em: <http://file://C:/Users/Usu\%C3\%A1rio/Downloads/ download(3)\%20(1).PDF > Acesso em: 22 abr. 2017.

NEUMANN, P. S.; DALBIANCO, V. P.; ZARNOTT, A.V. A política pública de extensão rural em assentamentos da reforma agrária: a construção de um sistema pluralista descentralizado. In: GRISA, C.; SCHNEIDER, S. (Orgs.). Políticas públicas de desenvolvimento rural no Brasil. 1. ed. Porto Alegre: UFRGS, v. 01, p. 401-428, 2015. Disponível em: < http://aspta.org.br/wp-content/uploads/2015/10/ Pol\%C3\%ADticas-P\%C3\%BAblicas-de-Desenvolvimento-Rural-no-Brasil.pdf > Acesso em: 16 abr. 2017. 
OLIVEIRA, S. C. et al. Assessment of credit restrictions to farmers in rural settlements' in the western region of the state of São Paulo, Brazil. Revista Brasileira de Gestão e Desenvolvimento Regional, v. 12, p. 70-90, 2016.

PEDROSO, M. T. M. Experiências internacionais com a agricultura familiar e o caso brasileiro: O desafio da nomeação e suas implicações práticas. In: BUAINAIN, A. M. et al. (Orgs.). O mundo rural no Brasil do século 21: a formação de um novo padrão agrário e agrícola. Brasília, DF : Embrapa, 2014.1182 p. Disponível em: <http://www.embrapa.br/hortalicas/busca-de-publicacoes/-/publicacao/994881/ experiencias-internacionais-com-a-agricultura-familiar-e-o-caso-brasileiro-odesafio-da-nomeacao-e-suas-implicacoes-praticas> Acesso em: 30 mar. 2017.

REZENDE, G. C. PROCERA: Institucionalidade, Subsídio e Eficácia. Revista de Economia Política, São Paulo, v. 21, n.4, 2001. Disponível em: < http://www. en.ipea.gov.br/agencia/images/stories/PDFs/TDs/td_0648.pdf $>$. Acesso em: 29 mar. 2019.

RINGLE, C.; SILVA, D.; BIDO, D. S. Modelagem de Equações Estruturais com utilização do Smartpls. Revista Brasileira de Marketing, v. 13, n. 2, p. 54-71, 2014. Disponível em: <http://file://C:/Users/Usu\%C3\%A1rio/Downloads/Ringle_Silva_Bido_2014_Modelagem-de-Equacoes-Estrutur_31081.pdf> Acesso em: 12 abr. 2017.

ROCHA, F. E. C.; TROCCOLI, B. T.; ALBUQUERQUE, F. J. B. Desenvolvimento de modelo de avaliação de programa de incentivo à agricultura. Psicologia: Teoria e Pesquisa. [online], v. 27, n.1, p. 83-91, 2011. Disponível em: < http://www. scielo.br/pdf/ptp/v27n1/a11v27n1.pdf>. Acesso em: 03 nov. 2017.

RODRIGUES, C. M. Conceito de seletividade de políticas públicas e sua aplicação no contexto da política de extensão rural no Brasil. Cadernos de Ciência \& Tecnologia, Brasília,v.14,n.1,p.113-154,1997.Disponívelem:<http://www.alice.cnptia.embrapa. br/bitstream/doc/87857/1/Conceitodeseletividade.pdf>. Acesso em: 17 mar. 2017.

SABOURIN, E. Origens, evolução e institucionalização da política de agricultura familiar no Brasil. In: Seminário sobre Agricultura Familiar Brasileira, 2014, Brasília. Anais... Seminário sobre Agricultura Familiar Brasileira. Brasília: NEAD, 2014. v. 1. Disponível em: <https://www.researchgate.net/profile/Eric_Sabourin/ publication/270394315_Origens_evolucao_e_institucionalizacao_da_politica_ de_agricultura_familiar_no_Brasil_in_Seminario_sobre_Agricultura_Familiar_ 
Brasileira/links/54a96d010cf2eecc56e6c387/Origens-evolucao-e-institucionalizacao-da-politica-de-agricultura-familiar-no-Brasil-in-Seminario-sobre-Agricultura-Familiar-Brasileira.pdf> Acesso em: 01 fev. 2017.

SÃO PAULO (Estado). Secretaria de Agricultura e Abastecimento. Coordenadoria de Assistência Técnica Integral. Instituto de Economia Agrícola. Levantamento censitário de unidades de produção agrícola do Estado de São Paulo LUPA 2007/2008. São Paulo: SAA/CATI/IEA, 2008. Disponível em: <http://www. cati.sp.gov.br/projetolupa>. Acesso em: 23 nov. 2017.

SILVA, E. H. F. M. da; BERNARDES, E. M. Estrutura lógica como metodologia para avaliação de políticas públicas: uma análise do PRONAF. Revista de Administração Pública, Rio de Janeiro, v. 48, n. 3, p. 721-743, 2014. Disponível em: <http:// www.scielo.br/scielo.php?script=sci_arttext\&pid=S0034-76122014000300009\&lng=en\&nrm=iso $>$. Acesso em: 26 set. 2019.

VILELA, S. L. de. Perspectivas para a agricultura familiar brasileira: elementos de um projeto político de desenvolvimento rural, para além de uma "questão tecnológica”. In: DELGADO, G. C. BERGAMASCO, S. M. P. P. (Orgs.) Agricultura familiar brasileira: desafios e perspectivas de futuro. Brasília: Ministério do Desenvolvimento Agrário, 2017. 470 p. Disponível em: <http://www.mda.gov. br/sitemda/sites/sitemda/files/user_img_1756/Agricultura\%20Familiar_WEB_ LEVE.pdf> Acesso em: 22 mar. 2017. 